ARTICLE

\title{
A curved host and second guest cooperatively inhibit the dynamic motion of corannulene
}

\author{
Yang Yang (1) 1,2, Tanya K. Ronson (10 1, Zifei Lu (1) 1, Jieyu Zheng (10 ', Nicolas Vanthuyne (1) ${ }^{3}$,
} Alexandre Martinez (i) ${ }^{3} \&$ Jonathan R. Nitschke (i) ${ }^{1 凶}$

Biomolecular systems show how host-guest binding can induce changes in molecular behavior, which in turn impact the functions of the system. Here we report an artificial host-guest system where dynamic adaptation during guest binding alters both host conformation and guest dynamics. The self-assembled cage host employed here possesses concave walls and a chirotopic cavity. Complementarity between the curved surfaces of fullerenes and the inner surface of the host cavity leads the host to reconfigure stereochemically in order to bind these guests optimally. The curved molecule corannulene undergoes rapid bowl-to-bowl inversion at room temperature. Its inversion barrier is increased upon binding, however, and increased further upon formation of a ternary complex, where corannulene and a cycloalkane are both bound together. The chiral nature of the host also leads to clear differences in the NMR spectra of ternary complexes involving corannulene and one or the other enantiomer of a chiral guest, which enables the determination of enantiomeric excess by NMR.

\footnotetext{
${ }^{1}$ Department of Chemistry, University of Cambridge, Cambridge, UK. ${ }^{2}$ School of Chemistry and Materials Science, Jiangsu Normal University, Xuzhou, China.

${ }^{3}$ Aix Marseille Univ, CNRS, Centrale Marseille, iSm2, Marseille, France. ${ }^{凶}$ email: jrn34@cam.ac.uk
} 
$\mathrm{R}$ ecognition and binding processes involving biomolecules, such as enzyme-substrate, antibody-antigen, and protein-protein, are integral to living systems. In many cases, the conformations and shapes of biomacromolecules can change to fit the target substrate, in a process known as induced fit $^{1}$, or an auxiliary substance may bind to a host-guest complex to form a ternary complex, thus regulating or modulating the initial interaction ${ }^{2}$. Artificial molecular systems that mimic the sophisticated processes of induced fit and property regulation via ternary complex formation are challenging to design, but important in producing complex and functional systems of molecules ${ }^{3-5}$, and in understanding the molecular basis of binding in relevant biological processes.

Curved aromatic molecules are well-suited to investigations into complex host-guest phenomena, as their interactions principally involve dispersion forces. These include fullerenes ${ }^{6}$, which have promising applications as light-harvesting materials ${ }^{7}$, and corannulene, a bowl-shaped hydrocarbon that can be considered a subunit of a fullerene. Corannulene undergoes rapid bowl inversion at room temperature, with an energy barrier calculated to be $11.5 \mathrm{kcal}$ $\mathrm{mol}^{-18,9}$. Stabilization of the planar transition state to corannulene inversion has been achieved by threading this molecule through a cationic macrocycle ${ }^{10}$, and through compression within an anthracene-walled host ${ }^{11}$. Manipulation of corannulene to slow its inversion rate, in contrast, is a harder goal, having only been achieved through chemical modifications ${ }^{12}$.

Metal-organic cages provide confined inner phases that are usefully distinct from the outside environment ${ }^{13}$. These cavities can be used for the stabilization of labile species ${ }^{14,15}$, separations ${ }^{16-18}$, and catalysis ${ }^{19-24}$. Principles have been developed to enable the selective binding of specific guests, or classes of guests, from among many chemically similar prospective guests in solution ${ }^{25-30}$. These principles guide the design of artificial hosts to maximize host-guest interactions, with greater shape complementarity often leading to additional selectivity and affinity ${ }^{31,32}$.

In this work, we employ these ideas to prepare a host with curved walls, designed to interact with the curved $\pi$-conjugated surfaces of fullerenes and corannulene. Fullerenes induce a configurational change in the host, highlighting the impact of the guest on the host. The dynamic inversion of corannulene is restricted inside the host, demonstrating host impact on the guest. Further, co-guests form ternary complexes, resulting in further modulation of the behavior of both guests inside the cage. The corannulene guest also reports on the stereochemistry of a chiral co-guest.

\section{Results}

Synthesis and characterization of 1 . Subcomponent A was designed around a phosphangulene core (Fig. 1a), which was selected due to its chirality, large concave surface, and bowlshaped conformation that does not invert at room temperature ${ }^{33-35}$. Cage 1, with a spherical interior cavity, was obtained via the subcomponent self-assembly of A with 2formylpyridine and $\operatorname{zinc}(\mathrm{II})$ bis(trifluoromethylsulfonyl)imide $\left(\mathrm{Zn}\left(\mathrm{NTf}_{2}\right)_{2}\right)$ in acetonitrile.

The self-assembly of cage $\mathbf{1}$ from racemic A gives rise to a large set of stereochemical possibilities, as each metal center may adopt $\Delta$ or $\Lambda$ handedness, each ligand may possess $M$ or $P$ helicity. The observation of only one set of ligand proton signals in the ${ }^{1} \mathrm{H}$ NMR spectrum of $\mathbf{1}$ allows us to infer that self-assembly occurred stereoselectively in two ways. First, the two ligand enantiomers narcissistically self-sorted (Fig. 1a, c), such that each cage incorporated either only $M$ ligands or only $P$ ligands. Second, the $M$ or $P$ chirality of the ligands within a cage dictated the $\Delta$ or $\Lambda$ configuration of all of its metal centers. Thus, out of the two possible diastereomeric pairs of enantiomers of cage 1, labeled $T_{1}$ $\left(M_{4}-\Delta_{4}, P_{4}-\Lambda_{4}\right)$ and $T_{2}\left(M_{4}-\Lambda_{4}, P_{4}-\Delta_{4}\right)^{36}$, only one was observed. The X-ray crystal structure of 1 showed that 1 adopted exclusively the $T_{1}$ configuration (Fig. 1e).

Impact of guests on the host. Cage 1 was anticipated to bind $\mathrm{C}_{60}$ and $\mathrm{C}_{70}$ through the curved $\pi$ surfaces of its $\mathbf{A}$ residues ${ }^{34}$, in a similar fashion to Sygula's "buckycatcher" 37 . When 1 was prepared in the presence of $\mathrm{C}_{70}$ or $\mathrm{C}_{60}$, new ${ }^{1} \mathrm{H}$ NMR signals were observed, corresponding to the host-guest complex. Only one such set of signals was observed in the case of $\mathrm{C}_{70}$, whereas two sets of signals were observed for $\mathrm{C}_{60}$, suggesting the presence of two diastereomeric host configurations (Fig. 1c). After heating the reaction mixture at $70{ }^{\circ} \mathrm{C}$ for one week, the initial major set of signals disappeared, and the minor set increased to become the only product. X-ray crystallography revealed that $\mathbf{1}$ bound both $\mathrm{C}_{60}$ and $\mathrm{C}_{70}$ in the $T_{2}$ configuration (Fig. 1f, g).

Based upon X-ray data, the VOIDOO program ${ }^{38}$ was used to calculate the volume of $\mathbf{1}$ in the absence of a fullerene guest (Fig. 1e), and as its $\mathrm{C}_{60}$ (Fig. 1f) and $\mathrm{C}_{70}$ (Fig. 1g) adducts, providing volumes of $490 \AA^{3}, 718 \AA^{3}$ and $925 \AA^{3}$, respectively (Supplementary Fig. 85). The cavity size of $\mathbf{1}$ in the $T_{1}$ configuration is much smaller than that of the $T_{2}$ configuration adopted for the fullerene adducts. Larger $\mathrm{C}_{70}$ appears only to fit in the $T_{2}$ diastereomer, whereas smaller $\mathrm{C}_{60}$ can be accommodated in both configurations. We infer that the $T_{1}$ diastereomer of $\mathrm{C}_{60} \subset \mathbf{1}$ is kinetically favored, but that the $T_{2}$ adduct is favored thermodynamically, based upon the initial formation of the former, and its transformation into the latter upon heating (Fig. 1c). Intriguingly, within the chirotopic ${ }^{39}$ cavity of $\mathbf{1}$, the local symmetry of encapsulated $C_{70}$ is broken from $D_{5 \mathrm{~h}}$ to $D_{5}$, resulting in the splitting of its two highest-intensity ${ }^{13} \mathrm{C}$ NMR peaks into two sets of signals (Supplementary Fig. 26) ${ }^{40}$

Racemic triamine $\mathbf{A}$ was resolved into two enantiomers by chiral HPLC (Supplementary Section 8), enabling the construction of enantiopure $\left(P_{4}-\Lambda_{4}\right) \mathbf{1}$ and $\left(M_{4}-\Delta_{4}\right) \mathbf{1}$. The transformation of 1 from its $T_{1}$ configuration to $T_{2}$ following guest uptake was confirmed by CD studies of enantiopure 1 and its corresponding fullerene host-guest complexes (Fig. 1d and Supplementary Fig. 84). The CD signals around $240-320 \mathrm{~nm}$, corresponding to $\pi-\pi^{*}$ transitions, are correlated with the handedness of the metal vertices $^{41,42}$. The signals of $\mathrm{C}_{60} \subset \mathbf{1}$ and $\mathrm{C}_{70} \subset \mathbf{1}$ at this region are similar in magnitude, but with opposite signs to those of fullerene-free $\mathbf{1}$ for complexes prepared from a given enantiomer of $\mathbf{A}$ (Fig. 1d). The differences in size and chirality between the empty host and host-guest complexes illustrate that the cages can reconfigure stereochemically to adapt to large guests with curved surfaces.

Impact of the host on guests. Its concave ligands also enable $\mathbf{1}$ to encapsulate the bowl-shaped molecule corannulene selectively from among a series of polyaromatic hydrocarbons (Supplementary Section 2.5). Corannulene also experienced the chirotopic environment inside the cage, with its single-peak ${ }^{1} \mathrm{H}$ NMR spectrum splitting into two coupled signals. This observation is consistent with a local desymmetrization from the $C_{5 \mathrm{v}}$ point symmetry of free corannulene to the $C_{5}$ symmetry imposed by a chiral environment (Fig. 2a $)^{43}$. NMR integration indicated that only one corannulene was encapsulated. We infer 1 to remain in its $T_{1}$ configuration upon corannulene binding, based upon the NMR similarity to the free cage and crystallographic evidence, as noted below. The binding constant for corannulene within 1 was determined to be $K_{\mathrm{a}}=(1.1 \pm 0.1) \times 10^{3} \mathrm{M}^{-1}$ (Supplementary Section 3.1). 

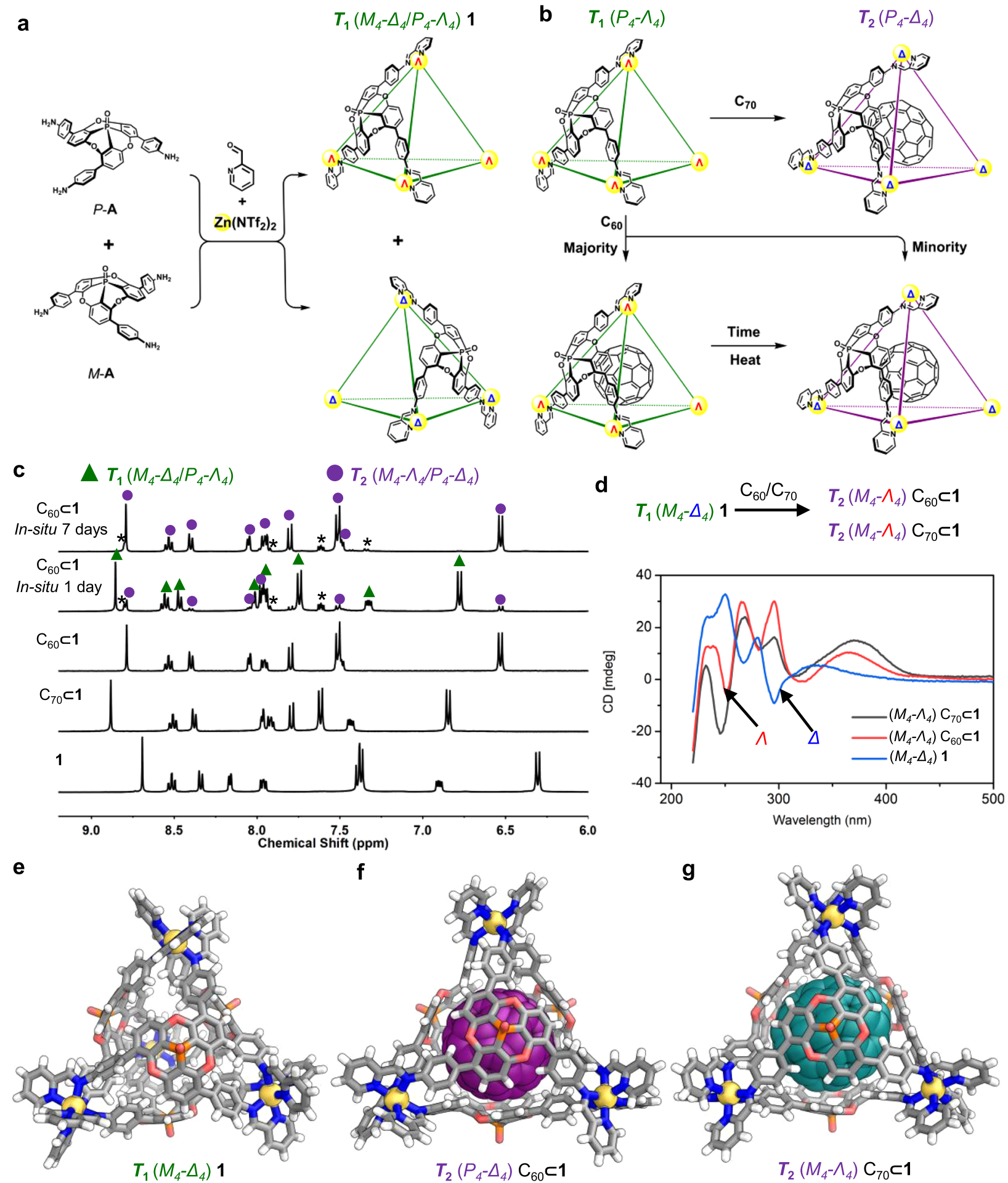

Fig. 1 Synthesis of cage $\mathbf{1}$ and induced fit of $\mathbf{C}_{\mathbf{6 0}}$ and $\mathbf{C}_{\mathbf{7 0}}$ guests. a The self-sorting preparation of cage $\mathbf{1}$ from chiral subcomponent $\mathbf{A}$ as a single pair of enantiomers. $\mathbf{b}$ The conversion of cage diastereomer $T_{1}$ into $T_{2}$ upon fullerene binding. $\mathbf{c}{ }^{1} \mathrm{H}$ NMR spectra of $\mathbf{1}$ and its $\mathrm{C}_{70}$ and $\mathrm{C}_{60}$ adducts, showing the evolution of the $\mathrm{C}_{60}$ adduct from the $T_{1}$ configuration (green triangles) into the $T_{2}$ (violet circles) over 7 days; residual 2-formylpyridine signals are labeled with asterisks. d CD spectra of $0.03 \mathrm{mM}$ acetonitrile solutions of the host and host-guest complexes prepared with enantiopure subcomponent $M$-A (spectra for assemblies with subcomponent $P$-A are shown in Supplementary Fig. 84). $\mathbf{g}$ X-ray crystal structures showing $\mathbf{1}$ in its preferred $T_{1}$ configuration (e) in the absence of a fullerene guest; and the $T_{2}$ configuration it adopts when binding (f) $C_{60}$ or $(\mathbf{g}) C_{70}$, respectively.

Cage 1 was also observed to bind pyrene, in a strongly cooperative fashion, such that only free $\mathbf{1}$ and (pyrene) ${ }_{2} \subset \mathbf{1}$ were observed by ${ }^{1} \mathrm{H}$ NMR. Competitive binding experiments indicated a higher affinity of $\mathbf{1}$ for corannulene over pyrene, which may result from the better fit of the bowl-shaped corannulene to the concave ligands (Supplementary Fig. 42). Planar coronene, which is structurally similar to curved corannulene, was not encapsulated. The slightly larger size may not be a decisive factor for the non-encapsulation of coronene here since $\mathbf{1}$ can adjust its configuration for large guests such as 

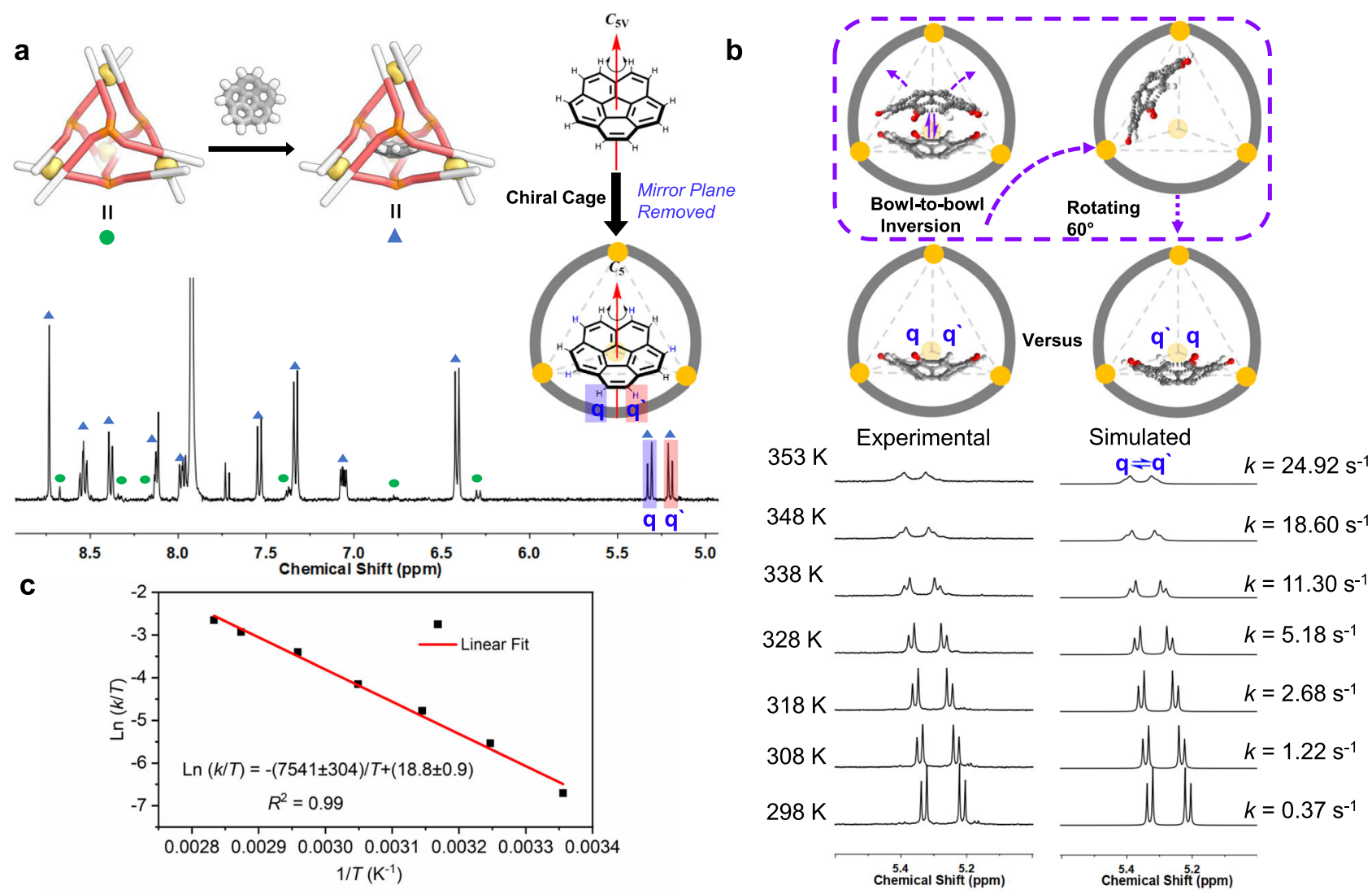

Fig. 2 Encapsulation of corannulene and its dynamic inversion. a ${ }^{1} \mathrm{H}$ NMR spectrum $\left(\mathrm{CD}_{3} \mathrm{CN}, 400 \mathrm{MHz}, 298 \mathrm{~K}\right)$ of 1 mixed with excess corannulene. Green circles correspond to $\mathbf{1}$ and light-blue triangles to corannulenec1. $\mathbf{b}$ Schematic illustration of the exchange of adjacent protons $\mathrm{H}_{\mathrm{a}}$ and $\mathrm{H}_{\mathbf{q}^{\prime}}$ during corannulene inversion, signals of encapsulated corannulene in variable temperature ${ }^{1} \mathrm{H}$ NMR spectra $\left(\mathrm{CD}_{3} \mathrm{CN}, 500 \mathrm{MHz}\right)$ of cage $\mathbf{1}$ with corannulene guests, and the corresponding simulated spectra obtained by line-shape analysis. After inversion, $\mathrm{H}_{\mathrm{q}}$ (red) has exchanged with $\mathrm{H}_{\mathrm{q}^{\prime}}$ (white) relative to the host. The rolling of the corannulene without inversion within the four ligand walls will not exchange protons $\mathrm{H}_{\mathrm{a}}$ and $\mathrm{H}_{\mathrm{q}^{\prime}}$. $\mathbf{c}$ Eyring plot for the inversion of corannulene inside of $\mathbf{1}$.

$\mathrm{C}_{70}$. As other cages that encapsulate corannulene were also observed to bind coronene $e^{11,16,44,45}$, the binding of corannulene but not coronene within 1 highlights the key role of shape complementarity in its binding preferences.

The chirotopic cavity of $\mathbf{1}$ enables the study of guest dynamics that would otherwise be concealed by symmetry 46 . The inversion of free corannulene in the solution cannot be studied by NMR, as its hydrogen atoms are all symmetry-equivalent ${ }^{9}$. Within $\mathbf{1}$, however, corannulene shows two sets of proton signals, because the adjacent protons $\mathrm{H}_{\mathrm{q}}$ and $\mathrm{H}_{\mathrm{q}^{\prime}}$ (Fig. 2b) are diastereotopic in a chiral space. When corannulene inversion occurs, $\mathrm{H}_{\mathrm{q}}$ and $\mathrm{H}_{\mathrm{q}^{\prime}}$ exchange, as observed by EXSY NMR (Supplementary Fig. 82). VT ${ }^{1} \mathrm{H}$ NMR showed that the signals of the encapsulated corannulene broaden with increased temperature while the signals for the host remain sharp, indicating bowl-to-bowl inversion becomes faster at higher temperatures (Fig. 2b). The exchange rate constants $k$ were obtained through line-shape analyzes (Supplementary Section 4). Based on an Eyring plot (Fig. 2c), the activation energy $\Delta G^{\ddagger}(298 \mathrm{~K})$ was determined to be $17.9 \pm 0.3 \mathrm{kcal} \mathrm{mol}^{-1}$, which is notably higher than the experimentally-determined value for a monosubstituted corannulene $\left(10.3 \mathrm{kcal} \mathrm{mol}^{-1} \text { at } 206 \mathrm{~K}\right)^{8}$ and the extrapolated value for free corannulene $\left(11.5 \mathrm{kcal} \mathrm{mol}^{-1} \text { at } 298 \mathrm{~K}\right)^{9}$.

Macrocyclic ExBox ${ }^{4+}$ was found to accelerate the bowl-to-bowl inversion of corannulene bound within it, by stabilizing the planar transition state ${ }^{10}$. We infer that cage $\mathbf{1}$, in contrast, acted to stabilize the ground state of curved corannulene through binding to the curved inner surface of the cage. Thus, encapsulation inside 1 raises the barrier to corannulene inversion, provided the transition state is not also stabilized.

Heterotropic guest interactions inside the cage. Corannulene may be considered an elementary subunit of a fullerene, albeit with reduced curvature and size. Since corannulene only forms a 1:1 host-guest complex with $\mathbf{1}$, we infer that space remains to accommodate a second guest. Cycloalkanes $\left(\mathrm{C}_{n} \mathrm{H}_{2 n}\right)$ with five to eight carbons were found to be suitable second guests, forming ternary complexes. The encapsulation of a second guest was signaled by shifts in the ${ }^{1} \mathrm{H}$ NMR spectra (Supplementary Section 2.6).

Ternary complexes were observed to form for guests that did not bind in the absence of corannulene, such as cyclohexane. Upon addition of excess cyclohexane to a solution of 1 containing corannulene, a new singlet was observed at $-3.58 \mathrm{ppm}$ for encapsulated cyclohexane, upfield shifted by $5.05 \mathrm{ppm}$ compared to the free guest (Fig. 3a). The encapsulated corannulene was also shifted further upfield, and host signals shifted downfield, as compared with corannulenec1. DOSY NMR indicated the same diffusion coefficient for cage $\mathbf{1}$ and its corannulene and $\mathrm{C}_{6} \mathrm{H}_{12}$ guests (Fig. 3a). A ${ }^{1} \mathrm{H}$ NOESY experiment indicated spatial proximity between the second guest and the encapsulated corannulene (Supplementary Fig. 49). The formation of $\mathrm{C}_{6} \mathrm{H}_{12} \bullet$ corannulene $\mathrm{l} \mathbf{1}$ was also evidenced by ESI-MS. The binding constants $K_{\mathrm{a} 1}$ (for corannulene) and $K_{\mathrm{a} 2}$ (for cycloalkanes) are shown in Supplementary Table 1.

The X-ray crystal structure of $\mathrm{C}_{6} \mathrm{H}_{12} \bullet$ corannulenecl (Fig. 3b) further verified the formation of the ternary complex, with the 

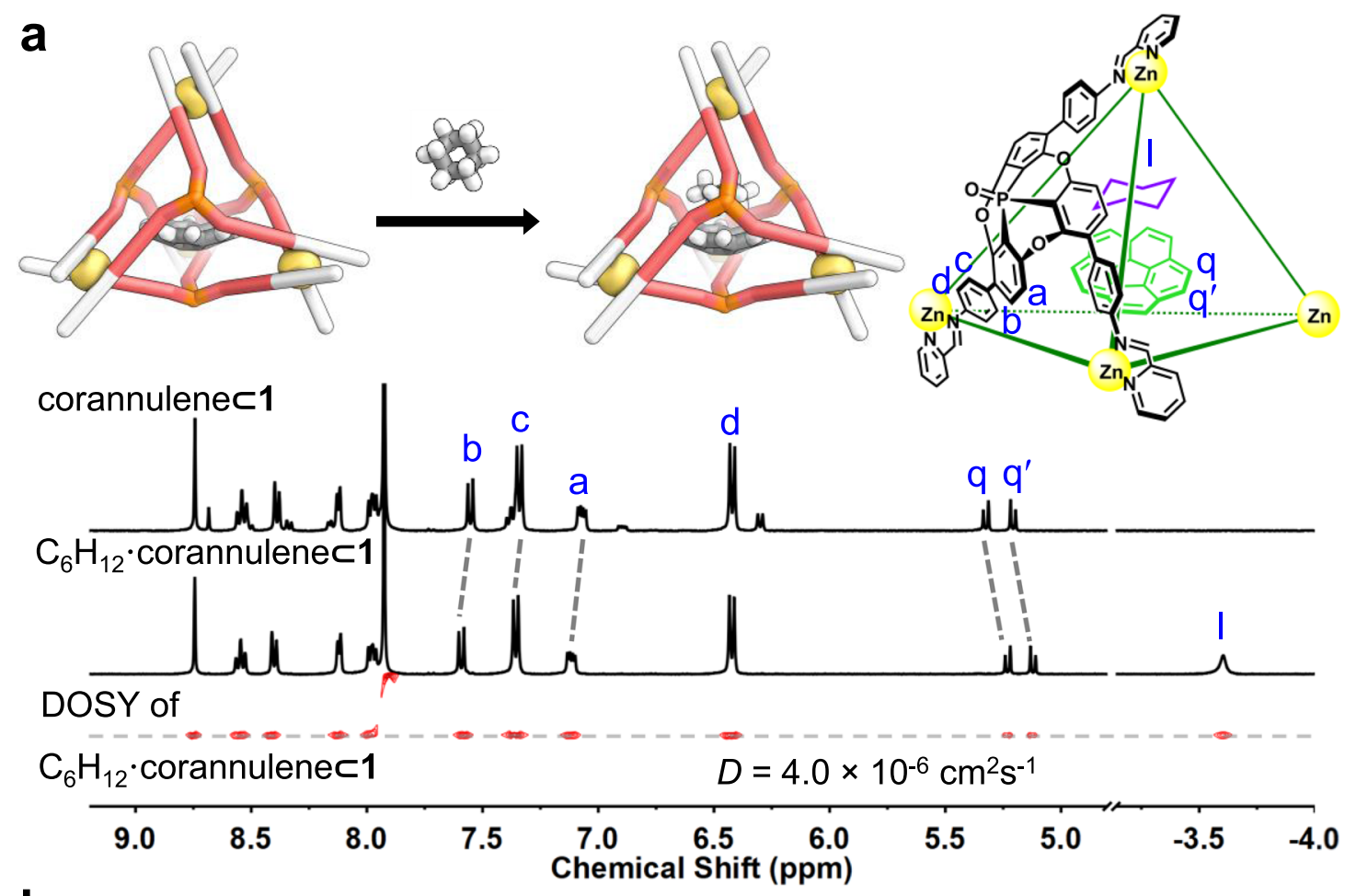

b
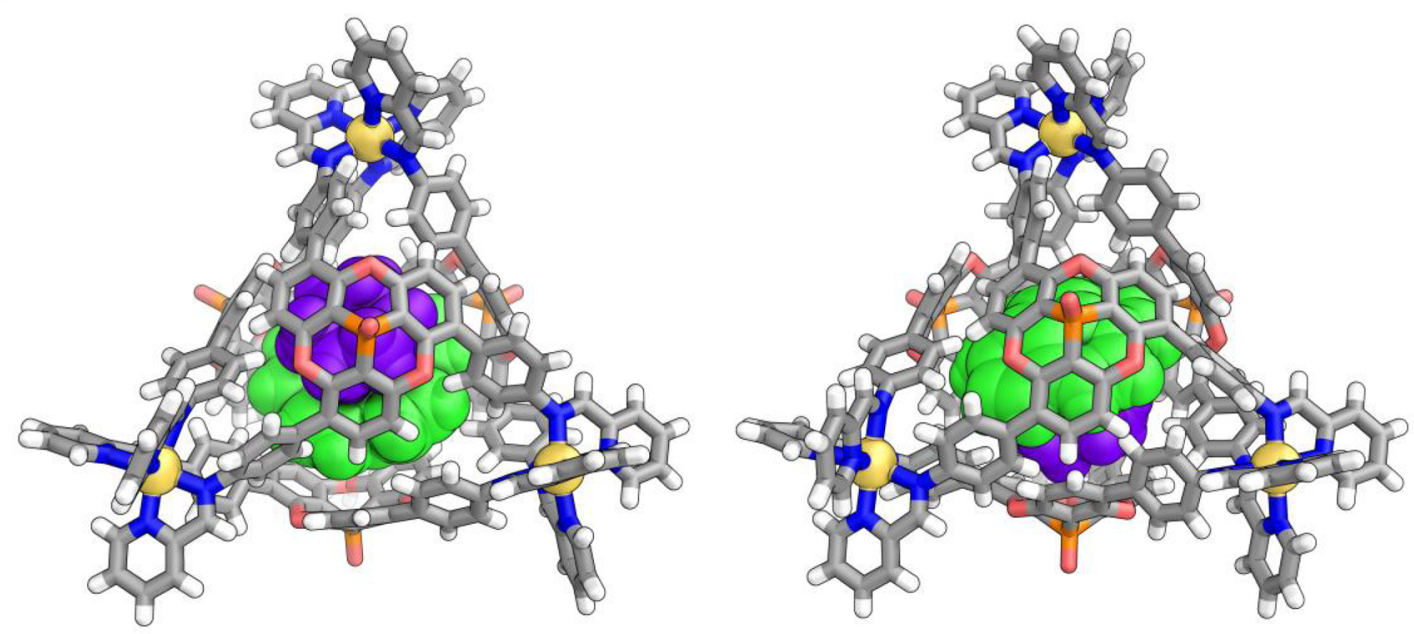

Fig. 3 Ternary complex formation. a Scheme of the binding of corannulene and cyclohexane within $\mathbf{1}$, and comparison of the ${ }^{1} \mathrm{H} N M R$ spectra $\left(\mathrm{CD}_{3} \mathrm{CN}_{\text {, }}\right.$ $400 \mathrm{MHz}, 298 \mathrm{~K}$ ) of corannulene $\mathrm{1}$ and $\mathrm{C}_{6} \mathrm{H}_{12} \bullet$ corannulenec $\mathbf{1}$, together with the ${ }^{1} \mathrm{H}$ DOSY spectrum of $\mathrm{C}_{6} \mathrm{H}_{12} \bullet$ corannulenec1. b Two views of the cationic part of the crystal structure of $\mathrm{C}_{6} \mathrm{H}_{12} \bullet$ corannulenec $\mathbf{1}$, showing cyclohexane in purple and corannulene in green.

host in the smaller $T_{1}$ configuration. Although the guests exhibited evidence of thermal motion, the positions and orientations of both guests were clear, with cyclohexane nestled inside the concavity of corannulene, which in turn stacked with the concave cage ligand.

In the presence of a co-encapsulated cycloalkane, corannulene inversion was no longer observed by signal coalescence in the NMR even at $348 \mathrm{~K}$ (Supplementary Figs. 77-80). Line shape analysis (Supplementary Fig. 81) indicated an energetic barrier $\left(\Delta G^{\ddagger}\right)$ to corannulene inversion at least $3.7 \mathrm{kcal} \mathrm{mol}^{-1}$ greater for $\mathrm{C}_{8} \mathrm{H}_{16} \cdot$ corannulene $\subset \mathbf{l}$ than for corannulene $\mathrm{l}$ at $348 \mathrm{~K}$, cumulative with the $6 \mathrm{kcal} \mathrm{mol}^{-1}$ barrier increase due to encapsulation within 1 (Fig. 2b). The second guest within the corannulene bowl takes up space, further inhibiting inversion and reinforcing the effect of the concave ligands of $\mathbf{1}$ in stabilizing the bowl state of corannulene.
The inversion of cyclohexane from one chair conformation to the other was also suppressed in $\mathrm{C}_{6} \mathrm{H}_{12} \bullet$ corannulenec $\mathbf{1}$. Upon lowering the temperature to $243 \mathrm{~K}$, two separate broad peaks for the equatorial and axial protons of encapsulated cyclohexane were observed, which collapsed into a single peak and sharpened above $253 \mathrm{~K}$ (Supplementary Fig. 76). A ring-flip barrier of $9.70 \mathrm{kcal} \mathrm{mol}^{-1}$ for cyclohexane was reported at $206.5 \mathrm{~K}^{47}$, whereas its $\Delta G^{\ddagger}$ of inversion inside $\mathrm{C}_{6} \mathrm{H}_{12} \bullet$ corannulene $C \mathbf{1}$ was extrapolated to be $10.65 \pm 0.03$ $\mathrm{kcal} \mathrm{mol}^{-1}$ at this temperature ${ }^{47}$. Co-encapsulation within a single host thus slows down the dynamic motion of both guests, with each guest having an influence upon the dynamics of the other within the host-guest-guest system.

Stereochemical communication between guests. Enantiopure $R$ 3-methyl-2-butanol (R-MB) also bound within 1 together with 


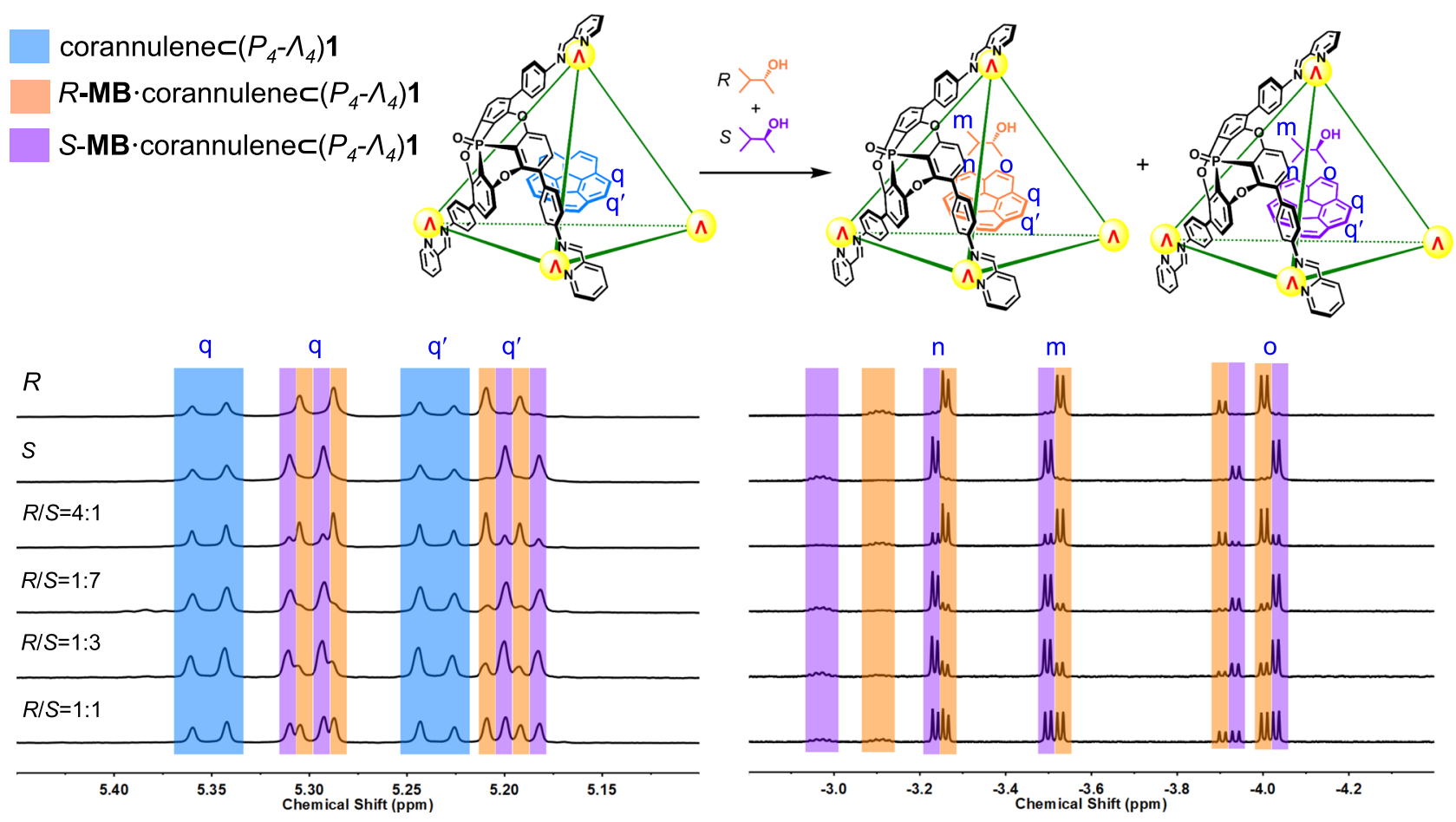

Fig. 4 Stereochemical information reported by corannulene and 3-methyl-2-butanol enantiomeric excess (ee) determinations by NMR. Partial ${ }^{1} \mathrm{H}$ NMR spectra $\left(\mathrm{CD}_{3} \mathrm{CN}, 500 \mathrm{MHz}, 298 \mathrm{~K}\right)$ of solutions of enantiopure cage $\left(P_{4}-\Lambda_{4}\right) \mathbf{1}$ together with corannulene and different ratios of $R / S$-3-methyl-2-butanol $(R / S-\mathbf{M B})$ showing the bound guest signals. The peaks of corannulenec $\left(P_{4}-\Lambda_{4}\right) \mathbf{1}, R$-MB•corannulenec $\left(P_{4}-\Lambda_{4}\right) \mathbf{1}$ and $S-\mathbf{M B} \bullet c o r a n n u l e n e c\left(P_{4}-\Lambda_{4}\right) \mathbf{1}$ are marked in light blue, orange, and violet, respectively.

corannulene, requiring this co-guest to bind (Supplementary Section 2.7). The signals of encapsulated corannulene are sensitive to the stereochemistry of the second guest, splitting into two sets due to the formation of the diastereomers $R$-MB.corannulene $C\left(M_{4}-\Delta_{4}\right) \mathbf{1}$ and $R$-MB•corannulene $C\left(P_{4}-\Lambda_{4}\right) \mathbf{1}$ (Supplementary Fig. 64). Two well-separated sets of signals of equal intensity were observed for the encapsulated $R-\mathbf{M B}$, with upfield guest shifts together with a DOSY NMR spectrum providing evidence of encapsulation (Supplementary Fig. 65). No difference in the integrated intensities of the host-guest complexes were observed, indicating that the two enantiomeric complexes corannulene $\subset\left(M_{4}-\Delta_{4}\right) \mathbf{1}$ and corannulene $C\left(P_{4}-\Lambda_{4}\right) \mathbf{1}$ do not discriminate when binding the enantiomers of $\mathbf{M B}$.

Enantiopure cage $\left(P_{4}-\Lambda_{4}\right) \mathbf{1}$ together with corannulene and racemic MB produced similar ${ }^{1} \mathrm{H}$ NMR spectra, corroborating non-enantioselective guest binding (Fig. 4). The aromatic shielding effects of corannulenec 1 shift the proton signals of the bound guests upfield by more than $5 \mathrm{ppm}$, into the spectral region below $0 \mathrm{ppm}$, without interfering signals. The ratio between $R$-MB and $S$-MB bound inside corannulenec $\mathbf{l}$ is inferred to reflect the ratio between these enantiomers in solution, due to the lack of enantioselectivity in binding. These two factors enable corannulenecl to be used as an NMR spectroscopic probe for the direct determination of the enantiomeric excess (ee) of chiral MB.

To support this hypothesis, $\mathbf{M B}$ mixtures with different degrees of ee were combined with $\left(P_{4}-\Lambda_{4}\right) \mathbf{1}$ and corannulene (Supplementary Section 5). The integrations of the proton signals of encapsulated MB reflected well the ratios between the $R$ and $S$ enantiomers of the guest (Supplementary Table 2). The $R / S$ ratios were also reflected in the integrals of the signals of the encapsulated corannulene (Fig. 4). All three elements of the system-the two guests and the host-thus collectively constructed and reported upon the chirotopic cavity environment.
The concave panels of host $\mathbf{1}$ enabled it to bind fullerenes well, reconfiguring stereochemically in order to optimize host-guest contact. The chirotopic space within $\mathbf{1}$ enabled the exploration of its stabilization of the bowl-shaped ground state of corannulene, which in turn served to "pad" the cavity in order to optimize the binding of cycloalkanes in ternary complexes. Ternary complexes involving chiral guests can report upon the guest's stereochemistry. The ability of the guests to influence each other's dynamics suggests novel applications where guest motions might be geared togetherfor example, the ring-flipping of corannulene might compress a second guest, thus accelerating a reaction with an unfavorable volume of activation, such as an intramolecular cycloaddition.

\section{Data availability}

The authors declare that all data supporting the findings of this study are included within the article and its Supplementary Information, and are also available from the authors upon request. Crystallographic data for the structures reported in this paper have been deposited at the Cambridge Crystallographic Data Center, under the deposition numbers $2068668(1), 2068666\left(\mathrm{C}_{60} \subset \mathbf{1}\right), 2068667\left(\mathrm{C}_{70} \subset \mathbf{1}\right)$, and $2068665\left(\mathrm{C}_{6} \mathrm{H}_{12} \bullet\right.$ corannulene $\left.\subset \mathbf{1}\right)$. Copies of these data can be obtained free of charge via www.ccdc.cam.ac.uk/ data_request/cif.

Received: 11 May 2021; Accepted: 10 June 2021;

Published online: 02 July 2021

\section{References}

1. Koshland, D. E. Jr. The key-lock theory and the induced fit theory. Angew. Chem. Int. Ed. 33, 2375-2378 (1995).

2. Li, W., Johnson, D. J. D., Esmon, C. T. \& Huntington, J. A. Structure of the antithrombin-thrombin-heparin ternary complex reveals the antithrombotic mechanism of heparin. Nat. Struct. Mol. Biol. 11, 857-862 (2004).

3. Ray, D., Foy, J. T., Hughes, R. P. \& Aprahamian, I. A switching cascade of hydrazone-based rotary switches through coordination-coupled proton relays. Nat. Chem. 4, 757-762 (2012). 
4. Miljanić, O. Š. Small-molecule systems. Chem. Chem. 2, 502-524 (2017).

5. Lubbe, A. S., van Leeuwen, T., Wezenberg, S. J. \& Feringa, B. L. Designing dynamic functional molecular systems. Tetrahedron 73, 4837-4848 (2017).

6. Hirsch A., Brettreich M. Fullerenes: Chemistry and Reactions. John Wiley \& Sons, 2006.

7. Lai, Y.-Y., Cheng, Y.-J. \& Hsu, C.-S. Applications of functional fullerene materials in polymer solar cells. Energy Environ. Sci. 7, 1866-1883 (2014).

8. Scott, L. T., Hashemi, M. M. \& Bratcher, M. S. Corannulene bowl-to-bowl inversion is rapid at room temperature. J. Am. Chem. Soc. 114, 1920-1921 (1992).

9. Seiders, T. J., Baldridge, K. K., Grube, G. H. \& Siegel, J. S. Structure/energy correlation of bowl depth and inversion barrier in corannulene derivatives: combined experimental and quantum mechanical analysis. J. Am. Chem. Soc. 123, 517-525 (2001).

10. Juricek, M. et al. Induced-fit catalysis of corannulene bowl-to-bowl inversion. Nat. Chem. 6, 222-228 (2014).

11. Kishida, N. et al. Anisotropic contraction of a polyaromatic capsule and its cavity-induced compression effect. J. Am. Chem. Soc. 142, 9599-9603 (2020).

12. Abdourazak, A. H., Sygula, A. \& Rabideau, P. W. "Locking" the bowl-shaped geometry of corannulene: cyclopentacorannulene. J. Am. Chem. Soc. 115, 3010-3011 (1993).

13. Cook, T. R., Zheng, Y.-R. \& Stang, P. J. Metal-organic frameworks and selfassembled supramolecular coordination complexes: comparing and contrasting the design, synthesis, and functionality of metal-organic materials. Chem. Rev. 113, 734-777 (2013).

14. Mal, P., Breiner, B., Rissanen, K. \& Nitschke, J. R. White phosphorus is airstable within a self-assembled tetrahedral capsule. Science 324, 1697-1699 (2009).

15. Iwasawa, T., Hooley, R. J. \& Rebek, J. Stabilization of labile carbonyl addition intermediates by a synthetic receptor. Science 317, 493-496 (2007).

16. Zhang, D., Ronson, T. K., Lavendomme, R. \& Nitschke, J. R. Selective separation of polyaromatic hydrocarbons by phase transfer of coordination cages. J. Am. Chem. Soc. 141, 18949-18953 (2019).

17. Fuertes-Espinosa, C. et al. Purification of uranium-based endohedral metallofullerenes (EMFs) by selective supramolecular encapsulation and release. Angew. Chem. Int. Ed. 57, 11294-11299 (2018)

18. Liu, M. et al. Barely porous organic cages for hydrogen isotope separation. Science 366, 613-620 (2019).

19. Fang, Y. et al. Catalytic reactions within the cavity of coordination cages. Chem. Soc. Rev. 48, 4707-4730 (2019).

20. Zhang, Q., Rinkel, J., Goldfuss, B., Dickschat, J. S. \& Tiefenbacher, K. Sesquiterpene cyclizations catalysed inside the resorcinarene capsule and application in the short synthesis of isolongifolene and isolongifolenone. Nat. Catal. 1, 609-615 (2018)

21. Koo, J. et al. Gigantic porphyrinic cages. Chem 6, 3374-3384 (2020).

22. Fuertes-Espinosa, C. et al. Supramolecular fullerene sponges as catalytic masks for regioselective functionalization of $\mathrm{C}_{60}$. Chem 6, 169-186 (2020)

23. Martí-Centelles, V., Lawrence, A. L. \& Lusby, P. J. High activity and efficient turnover by a simple, self-assembled "artificial diels-alderase". J. Am. Chem. Soc. 140, 2862-2868 (2018).

24. Takezawa, H., Shitozawa, K. \& Fujita, M. Enhanced reactivity of twisted amides inside a molecular cage. Nat. Chem. 12, 574-578 (2020).

25. Santacroce, P. V. et al. Conformational control of transmembrane $\mathrm{Cl}$ transport. J. Am. Chem. Soc. 129, 1886-1887 (2007).

26. Pandurangan, K. et al. Unexpected self-sorting self-assembly formation of a [4:4] sulfate:ligand cage from a preorganized tripodal urea ligand. Angew. Chem. Int. Ed. 54, 4566-4570 (2015).

27. Li, R.-J., Holstein, J. J., Hiller, W. G., Andréasson, J. \& Clever, G. H. Mechanistic interplay between light switching and guest binding in photochromic $\left[\mathrm{Pd}_{2}\right.$ dithienylethene $\left.{ }_{4}\right]$ coordination cages. J. Am. Chem. Soc. 141, 2097-2103 (2019).

28. Cullen, W., Misuraca, M. C., Hunter, C. A., Williams, N. H. \& Ward, M. D. Highly efficient catalysis of the Kemp elimination in the cavity of a cubic coordination cage. Nat. Chem. 8, 231-236 (2016).

29. Jia, F. et al. Redox-responsive host-guest chemistry of a flexible cage with naphthalene walls. J. Am. Chem. Soc. 142, 3306-3310 (2020).

30. Omoto, K., Tashiro, S., Kuritani, M. \& Shionoya, M. Multipoint recognition of ditopic aromatic guest molecules via $\mathrm{Ag}-\pi$ interactions within a dimetal macrocycle. J. Am. Chem. Soc. 136, 17946-17949 (2014).

31. Chen, B., Holstein, J. J., Horiuchi, S., Hiller, W. G. \& Clever, G. H. Pd(II) coordination sphere engineering: pyridine cages, quinoline bowls, and heteroleptic pills binding one or two fullerenes. J. Am. Chem. Soc. 141 8907-8913 (2019).

32. Lister, F. G. A., Le Bailly, B. A. F., Webb, S. J. \& Clayden, J. Ligand-modulated conformational switching in a fully synthetic membrane-bound receptor. Nat. Chem. 9, 420-425 (2017)

33. Heskia, A., Maris, T. \& Wuest, J. D. Phosphangulene: a molecule for all chemists. Acc. Chem. Res. 53, 2472-2482 (2020).
34. Yamamura, M., Saito, T. \& Nabeshima, T. Phosphorus-containing chiral molecule for fullerene recognition based on concave/convex interaction. $J$. Am. Chem. Soc. 136, 14299-14306 (2014).

35. Krebs, F. C. et al. Synthesis, structure, and properties of 4,8,12-trioxa-12cphospha-4,8,12,12c-tetrahydrodibenzo[cd,mn]pyrene, a molecular pyroelectric. J. Am. Chem. Soc. 119, 1208-1216 (1997).

36. Zhang, D. et al. Temperature controls guest uptake and release from $Z_{4} \mathrm{~L}_{4}$ tetrahedra. J. Am. Chem. Soc. 141, 14534-14538 (2019).

37. Sygula, A., Fronczek, F. R., Sygula, R., Rabideau, P. W. \& Olmstead, M. M. A double concave hydrocarbon buckycatcher. J. Am. Chem. Soc. 129, 3842-3843 (2007).

38. Kleywegt, G. J. \& Jones, T. A. Detection, delineation, measurement and display of cavities in macromolecular structures. Acta Cryst. D50, 178-185 (1994).

39. Mislow, K. \& Siegel, J. Stereoisomerism and local chirality. J. Am. Chem. Soc. 106, 3319-3328 (1984).

40. Szymański, M. et al. Mechanochemical encapsulation of fullerenes in peptidic containers prepared by dynamic chiral self-sorting and self-assembly. Chem.Eur. J. 22, 3148-3155 (2016).

41. Howson, S. E. et al. Origins of stereoselectivity in optically pure phenylethaniminopyridinetris-chelates $\mathrm{M}\left(\mathrm{NN}^{\prime}\right)_{3}{ }^{\mathrm{n}+}(\mathrm{M}=\mathrm{Mn}, \mathrm{Fe}, \mathrm{Co}, \mathrm{Ni}$ and Zn). Dalton Trans. 40, 10416-10433 (2011).

42. Dragna, J. M. et al. In situ assembly of octahedral Fe(II) complexes for the enantiomeric excess determination of chiral amines using circular dichroism spectroscopy. J. Am. Chem. Soc. 134, 4398-4407 (2012).

43. Bandera, D., Baldridge, K. K., Linden, A., Dorta, R. \& Siegel, J. S. Stereoselective coordination of $C_{5}$-symmetric corannulene derivatives with an enantiomerically pure $\left[\mathrm{Rh}^{\mathrm{I}}\left(\mathrm{nbd}^{*}\right)\right]$ metal complex. Angew. Chem. Int. Ed. $\mathbf{5 0}$ 865-867 (2011).

44. Yoshizawa, M. et al. Discrete stacking of large aromatic molecules within organic-pillared coordination cages. Angew. Chem. Int. Ed. 44, 1810-1813 (2005).

45. Schmidt, B. M., Osuga, T., Sawada, T., Hoshino, M. \& Fujita, M. Compressed corannulene in a molecular cage. Angew. Chem. Int. Ed. 55, 1561-1564 (2016)

46. Zhu, H. et al. Pillararene host-guest complexation induced chirality amplification: a new way to detect cryptochiral compounds. Angew. Chem. Int. Ed. 59, 10868-10872 (2020).

47. Jensen, F. R., Noyce, D. S., Sederholm, C. H. \& Berlin, A. J. The energy barrier for the chair-chair interconversion of cyclohexane. J. Am. Chem. Soc. 82, $1256-1257$ (1960)

\section{Acknowledgements}

This work was supported by the Engineering and Physical Sciences Research Council (EPSRC, EP/P027067/1) and the European Research Council (695009). Y.Y. acknowledges the National Natural Science Foundation of China (No. 22071083) and the support of the Jiangsu Overseas Visiting Scholar Program from the Jiangsu Provincial Education Department. We thank Diamond Light Source for beamtime on Beamline I19 (CY21497) and the computing facilities of the CRCMM of Marseille. We also thank Dr. D. Zhang for the useful discussion.

\section{Author contributions}

J.R.N. and Y.Y. conceived the study, analyzed the results, and wrote the manuscript. Y.Y. performed the experiments. T.K.R. collected the X-ray data, T.K.R. and Y.Y. refined the structures. Z.L. performed the CD studies. J.Z. performed parts of the experiments. N.V. and A.M. resolved the ligands and determined the configurations. All authors discussed the results and edited the manuscript.

\section{Competing interests}

The authors declare no competing interests.

\section{Additional information}

Supplementary information The online version contains supplementary material available at https://doi.org/10.1038/s41467-021-24344-w.

Correspondence and requests for materials should be addressed to J.R.N.

Peer review information Nature Communications thanks the anonymous reviewer(s) for their contribution to the peer review of this work.

Reprints and permission information is available at http://www.nature.com/reprints

Publisher's note Springer Nature remains neutral with regard to jurisdictional claims in published maps and institutional affiliations. 
(c) (i) Open Access This article is licensed under a Creative Commons Attribution 4.0 International License, which permits use, sharing, adaptation, distribution and reproduction in any medium or format, as long as you give appropriate credit to the original author(s) and the source, provide a link to the Creative Commons license, and indicate if changes were made. The images or other third party material in this article are included in the article's Creative Commons license, unless indicated otherwise in a credit line to the material. If material is not included in the article's Creative Commons license and your intended use is not permitted by statutory regulation or exceeds the permitted use, you will need to obtain permission directly from the copyright holder. To view a copy of this license, visit http://creativecommons.org/ licenses/by/4.0/.

(C) The Author(s) 2021 